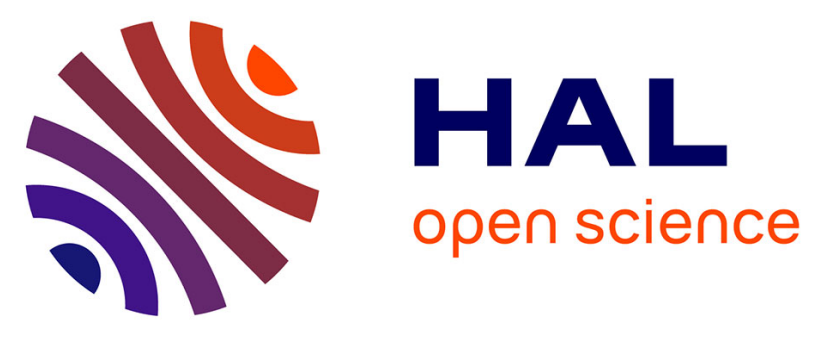

\title{
Mechanical properties of membranes composed of gel-phase or fluid-phase phospholipids probed on liposomes by atomic force spectroscopy
}

Oumaima Et Thakafy, N. Delorme, Cedric Gaillard, Cristelle Mériadec, Franck Artzner, Christelle Lopez, Fanny Guyomarc'H

\section{To cite this version:}

Oumaima Et Thakafy, N. Delorme, Cedric Gaillard, Cristelle Mériadec, Franck Artzner, et al.. Mechanical properties of membranes composed of gel-phase or fluid-phase phospholipids probed on liposomes by atomic force spectroscopy. Langmuir, 2017, 33 (21), pp.5117-5126. 10.1021/acs.langmuir.7b00363 . hal-01529481

\section{HAL Id: hal-01529481 \\ https://hal.science/hal-01529481}

Submitted on 13 Jul 2017

HAL is a multi-disciplinary open access archive for the deposit and dissemination of scientific research documents, whether they are published or not. The documents may come from teaching and research institutions in France or abroad, or from public or private research centers.
L'archive ouverte pluridisciplinaire HAL, est destinée au dépôt et à la diffusion de documents scientifiques de niveau recherche, publiés ou non, émanant des établissements d'enseignement et de recherche français ou étrangers, des laboratoires publics ou privés.

\section{다(1)(2)}

Distributed under a Creative Commons Attribution - ShareAlikel 4.0 International 
1 Mechanical properties of membranes composed of gel-phase or fluid-phase

2 phospholipids probed on liposomes by atomic force spectroscopy

3

4 Oumaima ET-THAKAFY ${ }^{\dagger}$, Nicolas DELORME ${ }^{\dagger}$, Cédric GAILLARD", Cristelle

5 MERIADEC ${ }^{\S}$, Franck ARTZNER $^{\S}$, Christelle LOPEZ $^{\ddagger}$, Fanny GUYOMARC' $\mathrm{H}^{{ }^{*}}$

6

$7 \doteqdot$ STLO, INRA, Agrocampus Ouest, 35000, Rennes, France

8 || UR BIA 1268 Biopolymères Interactions Assemblages, INRA, 44316 Nantes, France

9 §Institut de Physique de Rennes, UMR 6251, CNRS, Université de Rennes 1, 263 Av. Général

10 Leclerc, 35042 Rennes, France

$11 \dagger$ UMR CNRS 6283 Institut des Molécules et Matériaux du Mans, Université du Maine,

12 Université Bretagne-Loire, 72000 Le Mans, France

13 *Corresponding author: Fanny Guyomarc’h

14 Key words: small unilamellar vesicle; Phase state; Bending modulus; Young's modulus;

15 Atomic force microscopy

\section{Abstract}

17 In many liposome applications, the nanomechanical properties of the membrane envelope are

18 essential to ensure e.g. physical stability, protection or penetration into tissues. Of all factors,

19 the lipid composition and its phase behavior are susceptible to tune the mechanical properties

20 of membranes. To investigate this, small unilamellar vesicles (SUV; diameter $<200 \mathrm{~nm}$ ), 
21 referred to as liposomes, were produced using either the unsaturated 1,2-dioleoyl-sn-glycero-

22 3-phosphocholine (DOPC) or the saturated 1,2-dipalmitoyl-sn-glycero-3-phosphocholine

23 (DPPC) in aqueous buffer at $\mathrm{pH}$ 6.7. The respective melting temperatures of these

24 phospholipids were $-20^{\circ} \mathrm{C}$ and $41^{\circ} \mathrm{C}$. X-ray diffraction analysis confirmed that at $20^{\circ} \mathrm{C}$ DOPC

25 was in the fluid phase and DPPC was in the gel phase. After adsorption of the liposomes onto

26 flat silicon substrates, atomic force microscopy (AFM) was used to image and probe the

27 mechanical properties of the liposome membrane. The resulting force-distance curves were

28 treated using an analytical model based on the shell theory to yield the Young's modulus $(E)$

29 and the bending rigidity $\left(k_{C}\right)$ of the curved membranes. The mechanical investigation showed

30 that DPPC membranes were much stiffer $(E=116 \pm 45 \mathrm{MPa})$ than those of DOPC $(E=13 \pm$

$319 \mathrm{MPa})$ at $20^{\circ} \mathrm{C}$. The study demonstrates that the employed methodology allows

32 discrimination of the respective properties of gel- or fluid-phase membranes when in the

33 shape of liposomes. It opens perspectives to map the mechanical properties of liposomes

34 containing both fluid and gel phases or of biological systems.

\section{I. INTRODUCTION}

36 In the recent years, small unilamellar vesicles of phospholipids $(<\mu$ m diameter $)$ have gained

37 increasing interest in various liposome technologies, e.g. as drug delivery systems in

38 pharmacy or as protective cargo capsules for cosmetics, nutraceuticals or for food design ${ }^{1,2}$.

39 They are also interesting models to investigate and possibly control in vivo biological

40 signaling mechanisms involving extracellular vesicles such as the so-called exosomes ${ }^{3,4}$. The 
41 composition of the phospholipids, i.e. the acyl chains' saturation/unsaturation and length,

42 impacts their phase state in the liposomes at ambient temperatures ${ }^{5}$. This, in turn, is likely to

43 affect the mechanical properties of the liposomes, which are of paramount importance for

44 these applications. Mechanical properties direct the stability, size, shape and fusion of the

45 liposomes ${ }^{6-8}$ as well as the membrane fluidity/rigidity or permeability and hence their loading

46 capacity or their ability to penetrate tissues ${ }^{9-13}$. For example, the permeability of various

47 saturated polar lipid membranes to glucose strongly increases as the lipid undergoes gel-to-

48 liquid disordered $\left(l_{d}\right)$ phase transition ${ }^{14}$. As another example, milk sphingomyelin exhibited

49 maximum permeability at temperatures where gel-to- $l_{d}$ phase transition occurs ${ }^{13}$. This has

50 important consequences on the formulation and design of liposomes, as the desirable

51 mechanical properties will differ depending on the application and temperature, e.g. storage at

52 ambient temperature, transdermal delivery of drugs, etc. Experimental techniques to measure

53 the mechanical properties of liposomes, such as the pipette aspiration technique, osmotic or

54 mechanical compression, shear-induced or optical tweezers deformation ${ }^{7}$ are often designed

55 for large objects of the $\mu \mathrm{m}$ length scale. For liposomes at the nanoscale, such as small

56 unilamellar vesicles, indentation measurement using atomic force microscopy (AFM) has

57 proven a valuable and sensitive approach ${ }^{15-20}$. The liposomes, adsorbed onto a flat substrate,

58 are indented by the AFM with low penetration distances (i.e. the order of magnitude of the

59 membrane thickness) and at as low force values as down to the $\mathrm{pN}$. The major advantage of

60 AFM over a nano-indenter is also its imaging capacity, which allows to locate liposomes and 
61 to indent them centrally, even though not perfectly normally ${ }^{16}$. In a pioneering study, Laney et

62 al. ${ }^{17}$ extracted synaptic liposomes $(\sim 110 \mathrm{~nm}$ diameter $)$ from the electric organ of the electric

63 ray Torpedo californica, immobilized them by adsorption onto mica and measured elastic

64 moduli values in the range $0.2-1.3 \mathrm{MPa}$. Liang et al. ${ }^{19,2119,22}$ followed the same approach on

65 small (40-160 $\mathrm{nm})$ liposomes of egg phosphadidylcholine (mainly

66 stearoyloleoylphosphatidylcholine, SOPC) and found that the elastic modulus increased with

67 the addition of up to $50 \mathrm{~mol} \%$ cholesterol from $\sim 2$ to $13 \mathrm{MPa}$. However, these authors used

68 an adaptation of the Hertz model for their calculations that assumed the liposomes to be

69 homogeneous filled spheres. By implementing the shell deformation theory, Delorme and

70 Fery $^{16}$ obtained higher elasticity values of $\sim 110 \mathrm{MPa}$ by indenting DPPC

71 (dipalmitoylphophastidylcholine) and proposed that the Hertz model underestimated the

72 mechanical properties of the liposomes. However, due to its mono-unsaturation, egg PC has a

73 melting temperature $(\mathrm{Tm})$ of $-15^{\circ} \mathrm{C}$ and is therefore in the $l_{d}$ or liquid crystalline $(\mathrm{L} \alpha)$ phase at

$7420^{\circ} \mathrm{C}$, while the fully saturated DPPC is in the gel or solid-ordered $\left(s_{o}\right)$ phase $(\mathrm{Tm}=$

$\left.7541.7^{\circ} \mathrm{C}\right)^{22,23}$. Therefore, it is yet to assess whether the AFM indentation measurement

76 combined with the shell theory interpretation is sensitive enough to discriminate liposomes

77 with presumably different mechanical properties of their membranes, e.g. by comparing

78 saturated and unsaturated phospholipids in different physical phases at $20^{\circ} \mathrm{C}$.

79 When the membranes are spread as two-dimensional supported lipid bilayers (SLBs),

80 measurement of the rupture force of membranes using AFM indentation has proven to fully 
81 resolve mechanical differences between phospholipids with various chain lengths, saturation

82 degrees or head groups ${ }^{24}$. However, calculation of the SLBs' effective elasticity using

83 indentation of the membrane and the Hertz model requires careful and narrow experimental

84 conditions not to be affected by the support ${ }^{25}$ Furthermore, direct measurement on small

85 liposomes would encompass possible curvature effects. Indeed, their high membrane

86 curvature may affect their mechanical properties, as lateral intermolecular distances and

87 forces vary across the bilayer's thickness ${ }^{26,27}$. However, indentation measurements on 3D

88 vesicles may be either impossible ${ }^{28}$, require high deformation of the objects ${ }^{19}$ or somewhat

89 depend on the composition of the internal medium, if different from the surrounding

90 medium $^{29}$. For these reasons, there is interest to assess indentation measurement of the

91 mechanical properties of membranes directly on volumetric objects such as liposomes.

92 In the present study, the respective elasticities and bending rigidities of membranes of either

93 the unsaturated phospholipid dioleoylphosphatidylcholine (DOPC) or the saturated

94 phospholipid dipalmitoylphosphatidylcholine (DPPC) as shaped in the form of liposomes,

95 were measured at $20^{\circ} \mathrm{C}$ using $\mathrm{AFM}$ indentation and the shell theory. The results were

96 discussed in light of the respective phase states of the two phospholipids at $20^{\circ} \mathrm{C}$ and showed

97 that AFM indentation is a sensitive method to assess the mechanical properties of 3D

98 membrane objects at the nanoscale.

\section{EXPERIMENTAL METHODS}


101

102

103

104

105

106

107

108

109

110

111

112

113

114

115

116

117

118

119

120

\subsection{Materials}

Pure phospholipids 1,2-dioleoyl-sn-glycero-3-phosphocholine (DOPC; 18:1; >99\%) and 1,2dipalmitoyl-sn-glycero-3-phospholcholine (DPPC; 16:0; >99\%) were purchased from Avanti Polar Lipids (Alabaster, AL). PIPES (1,4-piperazinediethanesulfonic acid) buffer was prepared as: PIPES $10 \mathrm{mM}$ (purity $\geq 99 \%$; Sigma-Aldrich, Milwaukee, WI, USA), NaCl 50 $\mathrm{mM}$ (Sigma), and $\mathrm{CaCl}_{2} 10 \mathrm{mM}$ (Sigma) were dissolved in Milli-Q water and adjusted to $\mathrm{pH}$ 6.7 using $\mathrm{NaOH} 5 \mathrm{M}$.

\subsection{Preparation of liposomes}

Samples were prepared by dissolving appropriate quantity of the lipid powder of DOPC or DPPC in glass vials with chloroform/methanol $(4: 1 \mathrm{v} / \mathrm{v})$. The organic solvent was then evaporated at $40{ }^{\circ} \mathrm{C}$ under a stream of dry nitrogen. The dried lipid films were hydrated with PIPES-NaCl-CaCl$l_{2}$ buffer at $70^{\circ} \mathrm{C}$ to reach a final concentration of $0.1 \mathrm{wt}$. $\%$ lipids then thoroughly vortexed. Small unilamellar vesicles (SUV) were produced at $65^{\circ} \mathrm{C}$ by sonication using a Q700 equipment (Q-sonica, Newtown, CT, USA) and a microtip operating at 50\% amplitude $(\sim 400 \mathrm{~W})$ for $30 \mathrm{~min}$. After sonication, the SUV suspension was left to cool and equilibrate at room temperature $\left(20^{\circ} \mathrm{C}\right)$. The SUV produced according to this protocol will be designated as "liposomes" throughout this report.

\subsection{Dynamic light scattering (DLS)}

The size distribution and the average hydrodynamic diameter $\left(D_{h}\right)$ of the vesicles were measured in PIPES-NaCl-CaCl 2 buffer at $20^{\circ} \mathrm{C}$ by dynamic light scattering (DLS) on a 
121 Zetasizer Nano ZS (Malvern Instruments, Worcestershire, United Kingdom). Measurements

122 were carried out at a scattering angle of $173^{\circ}$ and a wavelength of $633 \mathrm{~nm}$. The average $\mathrm{D}_{\mathrm{h}}( \pm$

$1235 \mathrm{~nm}$ ) was calculated from the intensity distribution using conversion into an autocorrelation

124 function which is then analyzed with the Stokes-Einstein relation, assuming that particles had

125 a spherical shape. The viscosity of the solution was $1.003 \mathrm{mPa} . \mathrm{s}$ at $20^{\circ} \mathrm{C}$ and the refractive

126 index of the solvent was 1.33 .

\section{2.4. Differential scanning calorimetry (DSC)}

128 The thermotropic properties of DOPC or DPPC were measured on multilamellar vesicles

129 using a differential scanning calorimetry (DSC) Q1000 apparatus (TA Instruments,

130 Newcastle, USA). Multilamellar vesicles (MLV) were produced by rehydration of the lipid

131 films with PIPES-NaCl-CaCl 2 buffer at $65^{\circ} \mathrm{C}$ to reach a final concentration of $20 \mathrm{wt}$ \% lipids,

132 then thorough vortex mixing. MLV are preferred over unilamellar vesicles in order to

133 accommodate the high bilayer concentration. They also allow higher resolution of the DSC

134 thermograms thanks to higher cooperativity of the molecules ${ }^{30}$. The samples were introduced

135 in $20 \mu \mathrm{L}$ aluminum pans that were then hermetically sealed. An empty pan was used as a

136 reference. The samples were heated at $2^{\circ} \mathrm{C} \cdot \mathrm{min}^{-1}$ from $-40^{\circ} \mathrm{C}$ to $70^{\circ} \mathrm{C}$. The calibration of the

137 calorimeter was performed with indium standard (melting point $=156.66^{\circ} \mathrm{C}, \Delta \mathrm{H}$ melting $=$

$\left.13828.41 \mathrm{~J} . \mathrm{g}^{-1}\right)$. The thermal measurements were performed in triplicate. Standard parameters

139 were calculated by the TA software (Universal Analysis 2000, v 4.1 D).

140 2.5. Temperature-controlled X-ray diffraction (XRD) 
141 X-ray scattering experiments were performed on the home-made Guinier beamline at IPR ${ }^{31}$.

142 A two-dimensional Pilatus detector with sample to detector distance of $232 \mathrm{~mm}$ allowed the

143 recording of XRD patterns in the range $0.013 \AA^{-1}$ to $1.742 \AA^{-1}$, thus covering both the small

144 and wide-angles regions of interest to characterize the lamellar structures and to identify the

145 packing of the acyl chains, respectively. Diffraction patterns displayed series of concentric

146 rings as a function of the radial scattering vector $q=4 \pi \sin \theta / \lambda$, where $2 \theta$ is the scattering

147 angle and $\lambda=1.541 \AA$ is the wavelength of the incident beam. The channel to scattering vector

$148 \mathrm{q}$ calibration of the detector was carried out with silver behenate ${ }^{32}$. Small volumes (around 10

$149 \mu \mathrm{L}$ ) of samples containing DOPC or DPPC vesicles were loaded in thin quartz capillaries of

$1501.5 \mathrm{~mm}$ diameter (GLAS W. Muller, Berlin, Germany) and inserted in the set-up at a

151 controlled temperature.

152 2.6. Transmission electron microscopy (TEM)

153 The observation of DOPC and DPPC Liposomes by cryo-TEM was realized as described in

154 previous work ${ }^{33}$. The samples were prepared using a cryoplunge cryo-fixation device (Gatan,

155 Pleasanton, CA, USA) in which a drop of the aqueous suspension was deposited on to glow-

156 discharged holey-type carbon-coated grids (Ted Pella Inc., Redding, CA, USA). The TEM

157 grid was then prepared by blotting the drop containing the specimen to a thin liquid layer

158 remained across the holes in the support carbon film. The liquid film was vitrified by rapidly

159 plunging the grid into liquid ethane cooled by liquid nitrogen. The vitrified suspension of

160 liposomes was mounted in a Gatan 910 specimen holder that was inserted in the microscope 
161 using a CT-3500-cryotransfer system (Gatan, USA) and cooled with liquid nitrogen. TEM

162 images were then obtained from liposomes suspension preserved in vitreous ice and 163 suspended across a hole in the supporting carbon substrate. The samples were observed under 164 low dose conditions $\left(<10 \mathrm{e}^{-} \cdot \mathrm{A}^{2}\right)$, at $-178{ }^{\circ} \mathrm{C}$, using a JEM 1230 'Cryo' microscope (Jeol, 165 Japan) operated at $80 \mathrm{keV}$ and equipped with a LaB6 filament. All the micrographs were 166 recorded on a Gatan $1,35 \mathrm{~K} \times 1,04 \mathrm{~K} \times 12$ bit ES500W CCD camera.

\section{2.7. Atomic force microscopy (AFM)}

$168 \quad$ 2.7.1. Indentation of liposomes

169 Simple open liquid sample cells were fabricated by gluing small $\left(\sim 0.5 \times 1 \mathrm{~cm}^{2}\right)$ pieces of 170 silicon substrate (molecular orientation 100) onto diagnostic glass slides (Thermo Scientific, 171 Waltham, MA, USA). After thorough cleaning of the cell with ethanol, water and $\mathrm{UV} / \mathrm{O}_{3}$, the 172 liposome suspension equilibrated at $20^{\circ} \mathrm{C}$ was deposited onto the clean silicon surface then 173 left to incubate at $20^{\circ} \mathrm{C}$ for $30 \mathrm{~min}$. The droplet was then gently exchanged with PIPES-NaCl$174 \mathrm{CaCl}_{2}$ buffer at $20^{\circ} \mathrm{C}$ to remove the un-adsorbed liposomes. The sample was then imaged in 175 contact mode using an MFP-3D Bio AFM (Asylum Research, Santa Barbara, CA, USA), with 176 a typical scan rate of $1 \mathrm{~Hz}$ for $20 \times 20 \mu \mathrm{m}^{2}$ and $256 \times 256$ pixels images, silicon MLCT 177 probes (nominal spring constant $k \sim 0.03 \mathrm{~N}^{-1} \mathrm{~m}^{-1}$ - Bruker Nano Surfaces, Santa Barbara, CA, 178 USA) calibrated extemporaneously using the thermal noise method, and loading forces 179 typically below $1 \mathrm{nN}$. Upon adsorption onto the flat surface, the spherical liposomes deform 180 into spherical cap geometry. AFM imaging of large area (typical size) allows localization of 
181 the adsorbed liposomes, then closer images (typically $2 \times 2 \mu \mathrm{m}^{2}$ or less) were recorded and

182 sections were drawn across the images in order to measure the individual liposome's height

$183(\mathrm{H})$ and base width $(\mathrm{W})$. The AFM probe was then positioned above the center of each

184 liposome and individual force curves $(\mathrm{n}>60)$ were recorded with a set point of $200 \mathrm{pN}$, a

185 distance of $100 \mathrm{~nm}$ and a Z-piezo speed of $2 \mu \mathrm{m} . \mathrm{s}^{-1}$. In these conditions, indentation of the

186 AFM tip into the liposome did not exceed $\sim 5 \mathrm{~nm}$, thereby allowing measurement of the

187 mechanical properties in the elastic regime of the membrane. The approach curves were then

188 treated using the shell theory as described in the result section.

189 For data visualization and analysis, Gwyddion 2.47 software was also used, as a means to

190 deduce the local radius of curvature $\left(R_{c}\right)$ at the top of individual adsorbed liposomes over a

191 distance of $\sim 130 \mathrm{~nm}$ both sides of the apex (130 nm being the estimated radius of the

192 membrane area affected by indentation by a 20-nm radius MLCT probe). The $R_{c}$ values of

193 individual liposomes were input in the calculation of the Young modulus (see below).

194 Measurement of the local $R_{c}$ values at the apex of individual liposomes, instead of for the

195 complete objects, avoided errors due to imperfect (e.g. flattened) spherical cap geometry of

196 the liposome upon adsorption, and/or errors due to convolution by the AFM tip. The latter

197 may indeed overestimate lateral dimensions of the liposomes by as much as the tip diameter,

198 but can be avoided as long as near-normal contact is maintained between the tip and the

199 liposomes, which is the case when measuring $R_{c}$ at their apex.

$200 \quad$ 2.7.2. Measurement of the bilayer thickness 
201 Immediately after sonication at $65^{\circ} \mathrm{C}, 10 \mu \mathrm{g}$ of the hot lipid suspension were deposited onto

202 freshly cleaved mica in an Asylum Research open liquid cell, then incubated at $65^{\circ} \mathrm{C}$ for 60

203 min. Slow cooling of the samples was performed using a programmed incubator as in Murthy

204 et al. $^{34}$ to yield supported lipid bilayers (SLB). Once equilibrated at $20^{\circ} \mathrm{C}$, the bilayers were

205 extensively rinsed and exchanged with PIPES-NaCl- $\mathrm{CaCl}_{2}$ buffer. AFM imaging of the

206 bilayers was then performed in the same buffer and in contact mode using MSNL probe

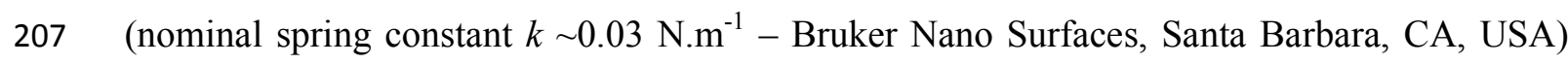

208 with the same imaging parameters already cited. The probes were calibrated

209 extemporaneously using the thermal noise method. Force spectroscopy curves were then

210 acquired at $20^{\circ} \mathrm{C}$ by using force-volume imaging of the bilayers (typically $10 \times 10 \mu \mathrm{m}^{2}$ or

211 less) with a typical set point of $20 \mathrm{nN}$ and a piezo speed of $2 \mu \mathrm{m} . \mathrm{s}^{-1}$.

\section{2.8. Statistical analysis}

213 The results are presented as mean value \pm standard deviation. Analysis of variance was

214 performed using the General Linear Model procedure of Statgraphics Plus version 5

215 (Statistical Graphics Corp., Englewood Cliffs, NJ). Differences were significant for $\mathrm{p}<0.05$.

217 III. RESULTS AND DISCUSSION

218 3.1. Phase state of DOPC and DPPC at $20^{\circ} \mathrm{C}$

219 The thermal phase behavior of unsaturated (18:1) DOPC and saturated (16:0) DPPC 220 phospholipids (chemical structures shown in Fig1.A) was examined using DSC and the 
221 results were correlated with the structural analysis performed by XRD. Fig1.B shows the

222 respective DSC heating thermograms of both lipids in the same conditions. For DOPC, the 223 thermogram shows a very low temperature of $L_{\beta}$ to $L_{\alpha}$ (gel to fluid) phase transition at $T_{m}=-$

$22420^{\circ} \mathrm{C}$, in good agreement with previous reports ${ }^{11,35,36}$. Meanwhile, the heating of DPPC 225 revealed two endotherms, characteristic of the $\mathrm{L}_{\beta}$ (gel) to $\mathrm{P}_{\beta}$, (ripple) transition at $226 \mathrm{~T}_{\mathrm{m}}=37.09{ }^{\circ} \mathrm{C}$ and of the $\mathrm{P}_{\beta}$, (ripple) to $\mathrm{L}_{\alpha}$ (fluid) transition at $\mathrm{T}_{\mathrm{m}}=41.01^{\circ} \mathrm{C}$, also in good 227 agreement with previous reports ${ }^{34,35,37}$. XRD experiments allowed identification of the lipid 228 phases at $20^{\circ} \mathrm{C}$ (Fig. 1C). For this, the MLV are interesting not only to investigate the lateral 229 packing of the acyl chains (at large q), but also to confirm the lamellar organization of the 230 phospholipid (at small q). For DOPC, the absence of diffraction peak at wide angles and a 231 lamellar organization characterized at small angles, confirmed the $\mathrm{L}_{\alpha}$ phase of DOPC at $20^{\circ} \mathrm{C}$.

232 DPPC multilamellar vesicles exhibited a single broad peak at $\mathrm{q} \sim 1.5 \AA^{-1}$ corresponding to the 233 formation of ordered phase packed in pseudo-hexagonal lattice and a lamellar organization at 234 small angles, showing the formation of a $\mathrm{L}_{\beta}$, organization of DPPC at $20^{\circ} \mathrm{C}$. The tilt of the 235 acyl chains may have been induced by the multilamellar organization of the DPPC molecules 236 in the vesicles. Since AFM experiments on DPPC molecules were performed in SUV, the 237 ordered phase state of DPPC molecules in SUV at $20^{\circ} \mathrm{C}$ was also proved by XRD 238 experiments performed on SUV of DPPC. As previously reported in literature ${ }^{38}$, the high 239 curvature of expected SUV of DPPC do not allow the recording of a peak at wide angles. 240 Nevertheless, the Small Angles X-ray Scattering could be performed upon heating of the 
241 SUV. Both high and low temperature spectra can be fitted as an individual membrane using

242 equation (1):

243

244

$$
I(q)=\frac{1}{q^{2}}\left[\frac{\sin \left(q \cdot e_{H G} / 2\right)}{q \cdot e_{H G}} \cdot e^{-(q \cdot r)^{2}}+\frac{\sin \left(q \cdot e_{C H 2} / 2\right)}{q \cdot e_{C H 2}}\right]^{2}
$$

245 with $\mathrm{e}_{\mathrm{HG}}$, the headgroup thickness, $\mathrm{e}_{\mathrm{CH} 2}$, the aliphatic chain thickness and $\mathrm{r}$ the rugosity of the 246 headgroup/water interface.

247 The full analysis demonstrates a contraction of $2 \AA$ of both $\mathrm{e}_{\mathrm{HG}}$ and $\mathrm{e}_{\mathrm{CH} 2}$ at the gel-fluid 248 transition at $40-44^{\circ} \mathrm{C}$ (Fig. 1D). This showed that the DPPC molecules in SUV are sensitive to 249 temperature and consequently in the gel phase at room temperature. In conclusion, DSC and 250 XRD confirmed that DOPC (unsaturated; $\mathrm{Tm}=-20^{\circ} \mathrm{C}$ ) and DPPC (saturated; $\mathrm{Tm}=41^{\circ} \mathrm{C}$ )

251 were respectively present in fluid and gel phases at $20^{\circ} \mathrm{C}$.

\section{3.2. Morphology of the liposomes at $20^{\circ} \mathrm{C}$}

253 Electron microscopy, dynamic light scattering (DLS) and AFM imaging were used to 254 characterize the morphology (size and shape) of the liposomes obtained after sonication (Fig 255 2). Cryo-TEM images showed that DOPC and DPPC vesicles were essentially unilamellar 256 and spherically shaped. However, while DOPC liposomes consistently exhibited circular 257 cross-sections (Fig 2A), DPPC could show both rounded and/or somewhat faceted 258 membranes (Fig 2D). The presence of angle facets was attributed to the physical gel state of 259 DPPC at $20^{\circ} \mathrm{C}^{39}$. Cryo-TEM images revealed variable liposome diameters (from tens to 
260 hundreds of $\mathrm{nm}$ ) which corresponded to the size distribution measured by DLS (Fig 2B, E).

261 For DOPC, the size distribution was monomodal with a mean diameter $\mathrm{D}_{\mathrm{h}}$ at $120 \pm 69 \mathrm{~nm}$

262 (Fig 2.B). Whereas, DPPC liposomes exhibited a shouldered size distribution with a mean

263 diameter $\mathrm{D}_{\mathrm{h}}$ of $132 \pm 73 \mathrm{~nm}$ for the whole distribution (Fig 2.E; Table1).

264 In the next step, the liposomes were immobilized by adsorption onto silicon to be first

265 imaged then indented using an AFM probe. Images recorded in contact mode showed that

266 DOPC and DPPC liposomes were perfectly stable on the flat substrate. However, it was

267 not possible to prevent non-destructive deformation due to adsorption, as previously

268 reported $^{19,40}$. The AFM images were also used to measure the height $H$ and basal width $W$

269 of adsorbed individual liposomes in order to prove that objects observed in AFM images

270 corresponded truly to liposomes. To do this, the adsorbed liposomes were considered to

271 adopt a spherical cap geometry and their volume was calculated as:

$$
V=\frac{\pi H}{6}\left(\frac{3}{4} W^{2}+H^{2}\right)
$$

272 From (Eq.2), the mean diameter of a sphere of equivalent volume was inferred and compared

273 with DLS data (Table 1; Figures 2B and E). The mean diameter values were of similar orders

274 of magnitude in both methods; and whatever the method used, DOPC liposomes always

275 exhibited smaller diameters than DPPC ones. This confirmed that the adsorbed objects visible

276 on the AFM images truly were liposomes. However, the mean diameter results measured by

277 AFM were higher than DLS probably because larger liposomes were preferably chosen out of 
278 large-area images (such as shown on Figure 2) to perform close-up views and indentation

279 measurements (Table1).

\section{3.3. Mechanical properties of liposomes as a function of phase state at $20^{\circ} \mathrm{C}$}

\section{$281 \quad 3.3 .1$. Bilayer thickness}

282 The average bilayer thickness $d$ was measured in the conditions used in this work:

283 temperature $20^{\circ} \mathrm{C}, \mathrm{pH}=6.7,50 \mathrm{mM} \mathrm{NaCl}$ and $10 \mathrm{mM} \mathrm{CaCl}_{2}$. This measurement was

284 performed using atomic force spectroscopy on SLB of DOPC or DPPC spread onto freshly

285 cleaved mica. Average values of d were obtained from measurements performed on various

286 regions of different samples $(n=50)$. In a typical force spectroscopy experiment, the AFM tip

287 approaches the surface until a mechanical contact with the SLB is established. Then, the

288 bilayer is elastically deformed by the AFM probe until the tip ruptures (breaks through) the

289 membrane, thereby coming into contact with the substrate. The indentation $v s$ force curves

290 exhibited breakthrough events ${ }^{23,34,41}$ where the jump-through distance (noted d) was

291 assimilated as the bilayer's thickness ${ }^{34}$. The limitations of this measurement were discussed

292 elsewhere ${ }^{42}$ and efforts were taken to regard bilayer compression. Fig.3A and C show three

293 examples of force-distance curves for each type of lipid bilayer. The $\mathrm{d}$ mean values obtained

294 were $3.91 \pm 0.46 \mathrm{~nm}$, and $4.93 \pm 0.47 \mathrm{~nm}$ for DOPC and DPPC bilayers, respectively. This

295 thickness difference between fluid and gel phases was perfectly detected by AFM

296 spectroscopy, in agreement with previous works ${ }^{25,43}$. In the literature, Nagles and Tristram-

297 Nagles $^{44}$ also determined the thicknesses of DOPC and DPPC fully hydrated bilayers using 
298 XRD and obtained a value of $3.6 \mathrm{~nm}$ for DOPC in the fluid phase and of $4.4 \mathrm{~nm}$ for DPPC in

299 the gel phase. It should be noted that DOPC has two unsaturated 18 hydrocarbon chains and

300 DPPC has two fully saturated 16 hydrocarbon chains (Fig1A). Unsaturation is the main

301 reason that adversely affected chain elongation and molecular packing ${ }^{45}$, making DPPC

302 bilayers more ordered and thicker than DOPC bilayers at room temperature.

303 Noteworthy, the value of the force at which the SLB ruptured (i.e., the breakthrough force)

304 was higher for DPPC $(2-3 \mathrm{nN})$ than for DOPC $(<1 \mathrm{nN})$, in agreement with their respective

305 phase states ${ }^{46-48}$. The lower absolute values found in the present study may be accounted for

306 the lower ionic strength and the sharper AFM tip (radius of MNSL tip $\sim 2 \mathrm{~nm}$ ) in comparison

307 to previous works.

\section{3.3.2. Mechanical properties of DOPC or DPPC liposomes:}

309 In this work, we show that AFM spectroscopy could be used to discriminate and compare the 310 mechanical properties of very small liposomes $(\sim 150 \mathrm{~nm})$ in different phase states.

311 Calculations of the Young modulus $E$ and bending modulus $k_{C}$, based on the shell theory

312 model, were done on DOPC or DPPC liposomes respectively in fluid or gel phase. In order to

313 limit the plastic deformation, force distance curves were recorded over $100 \mathrm{~nm}$ distance with a

314 set point of $200 \mathrm{pN}$ maximal force. Typical examples are shown in Fig. $3 \mathrm{~B}$ and D. In these

315 conditions, the approaching and retracting curves were superimposed, demonstrating the

316 elastic behavior of the membrane (not shown). The tip-membrane contact was defined as the

317 point where significant positive slope appeared. According to the shell theory developed by 
318 Reissner ${ }^{49}$ then Fery et al. ${ }^{16,50}$, the Young modulus $E$ of thin-shelled spherical micro-capsule

319 under a point load scales with the bilayer's stiffness, $k$, which was deduced from the slope of

320 the linear region of each force curve after the tip-membrane contact, i.e. in the small

321 deformation region (Fig 3.B and D). As $k$ strongly depends on the size of the individual

322 liposomes ${ }^{21}$, it has to be normalized by the local radius of curvature $R_{c}$ of the individual

323 liposomes ${ }^{16}$ to describe their mechanical properties. Calculation of $E$ requires the bilayers'

324 stiffness $k$, the local radius of curvature $R_{c}$ (see section 2.7.1), the bilayer's thickness $\mathrm{d}$

325 (Table1) and the Poisson ratio v, taken as 0.5:

$$
E=\frac{1}{C} \frac{k R_{C} \sqrt{3\left(1-v^{2}\right)}}{4 \mathrm{~d}^{2}}
$$

326 In equation 3, $C$ is a coefficient that accounts for the double deformation of an adsorbed shell

327 object, such as liposomes, upon indentation by the AFM tip. Indeed, whereas membrane

328 deformation occurs at the contact point between the tip and the liposome, simultaneous

329 deformation also occurs at the contact area between the liposome and the substrate ${ }^{51}$. In their

330 recent paper, Bery et al ${ }^{52}$ produced calculations for a correction factor, $C$, to be applied as a

331 function of the relative radii of the tip $(20 \mathrm{~nm})$ and liposome, and of the shell thickness

332 relative to the radius of the liposomes (Table 1). Since that dimensions were similar for both

333 the DOPC and DPPC liposomes, $C$ was $\sim 0.55$ for both types of liposomes.

334 In another way, the mechanical properties of liposomes can be also represented by the

335 bending rigidity $k_{C}$, which is expressed in terms of the same parameters and is also common in

336 the literature: 


$$
k_{C}=\frac{E \mathrm{~d}^{3}}{12\left(1-v^{2}\right)}
$$

337 Calculation of the Young's modulus, regardless of liposome size, showed that the DPPC

338 liposome membranes $\left(\mathrm{L}_{\beta}\right) E=116 \pm 45 \mathrm{MPa}$ were significantly more elastic at $20^{\circ} \mathrm{C}$ than

339 DOPC liposome membranes $\left(\mathrm{L}_{\alpha}\right)$ which exhibited a lower value of $E=13 \pm 9 \mathrm{MPa}$ (Fig.4.A

340 and $\mathrm{B} ; \mathrm{p}<0.05)$. Accordingly, the liposome membranes composed of DPPC were also stiffer

341 with $k_{C}=(15.5 \pm 6) \times 10^{-19} \mathrm{~J}\left(360 \mathrm{k}_{\mathrm{B}} \mathrm{T}\right)$ than those composed of DOPC with $k_{C}=(0.9 \pm 0.6)$

$342 \times 10^{-19} \mathrm{~J}(22 \mathrm{k}$ T) (Fig.4.C and D; $p<0.05)$. To verify that electrostatic repulsion was not

343 implicated in the force curves near the contact point, we compared the results acquired on

344 DPPC liposomes with varying surface charge, taken as the zeta potential and measured as

345 described in Makino et al. $^{53}$. The DPPC liposomes were positively charged with a zeta

346 potential of $18 \mathrm{mV}$ in PIPES buffer (ionic strength $\mathrm{I}=0.09$ ); and barely charged with a zeta

347 potential of $0.11 \mathrm{mV}$ in PBS buffer $\left(14 \mathrm{mM} \mathrm{KH}_{2} \mathrm{PO}_{4}, 200 \mathrm{mM} \mathrm{Na}_{2} \mathrm{HPO}_{4}, \mathrm{NaCl} 1.36 \mathrm{M}, \mathrm{KCl}\right.$

$34820 \mathrm{mM} ; \mathrm{I}=1.99 ; \mathrm{pH}=7.2$ ). The Young's modulus showed a mean value of $E=120 \pm 39 \mathrm{MPa}$

349 in PBS buffer and no significant difference was found between the Young moduli values

350 obtained in the two buffers $(\mathrm{p}>0.05)$. This result showed that force measurement of DPPC

351 membrane was not influenced by electrostatic interaction between the AFM probe and the

352 liposomes.

353 The Young modulus was also estimated using the $R_{c}$ of the whole liposome, which involves

354 the two parameters $H$ and $W$ (equation A.1). The results showed that the elasticity of DPPC 
355 was higher $(183 \mathrm{MPa})$ than that obtained by local $R_{c}(116 \mathrm{MPa})$, whereas $E$ was not

356 significantly changed for DOPC. With either methods of $R_{c}$ calculation, the results therefore

357 showed that AFM indentation was able to detect significant differences in the elasticities of

358 the two membranes depending on their fluid or gel phase state. However, the quantification of

359 the mechanical properties was found very sensitive to calculation of $R_{c}$ and to the liposome

360 geometry. For these reasons, we chose to compare the liposomes using the method based on

361 the local $R_{c}$ using Gwyddion in order to avoid any effect due to the form adopted by the

362 liposomes upon adsorption.

363 In conclusion, the structural differences between the fluid-phase DOPC and gel-phase DPPC

364 bilayers as evidenced by DSC and XRD, induced by the unsaturation of the acyl chains

365 (Fig1), resulted in significant difference in their respective mechanical responses. Hence,

366 AFM force spectroscopy proved a sensitive method to compare the mechanical properties of

367 small liposomes with different lipid compositions and phase states. Only few reports exist that

368 have evaluated these mechanical parameters for similar systems of lipid membrane in 3D,

369 especially for DOPC or DPPC using AFM spectroscopy (Table 2). Of all these studies, only

370 Liang et al..$^{21}$ used AFM spectroscopy comparatively, on liposomes with increasing addition

371 of cholesterol. Liang et al. ${ }^{21}$ obtained Young's modulus of $1.97 \pm 0.75 \mathrm{MPa}$, for liposomes in

372 the fluid phase composed of egg PC (mixture of saturated and unsaturated polar lipids; mostly

373 in the form of SOPC - stearoyl-oleoyl-phosphatidylcholine). Using an optical method,

374 Meleard et al. ${ }^{54}$ and Duwe et al. ${ }^{55}$ respectively obtained bending rigidities of $1.27 \pm 0.09 \times 10^{-}$ 
$375{ }^{19} \mathrm{~J}\left(31 \mathrm{k}_{\mathrm{B}} \mathrm{T}\right)$ or $1.15 \times 10^{-19} \mathrm{~J}\left(28 \mathrm{k}_{\mathrm{B}} \mathrm{T}\right)$ for liposomes composed of the saturated polar lipid

376 DMPC (1,2-dimyristoyl-sn-glycero-3-phosphocholine) in fluid phase at $40^{\circ} \mathrm{C}\left(\mathrm{Tm}=24^{\circ} \mathrm{C}\right)$.

377 Rawicz et al. $^{45}$ found values of $\sim 0.9 \times 10^{-19} \mathrm{~J}$ for bilayers of various synthetic 18:1

378 phospholipids. Another group, Hantz et al. ${ }^{56}$ used the osmotic swelling method and found

379 values of the Young's modulus of $15 \mathrm{MPa}$ for DOPC liposomes in the fluid phase at $20^{\circ} \mathrm{C}$.

380 Delorme and Fery ${ }^{16}$ obtained Young's moduli values of $110 \pm 15 \mathrm{MPa}$ for DPPC liposomes in

381 the gel phase. Taking only account of the phase state conditions, the values available in the

382 literature (Table 2) are in the same order of magnitude in comparison to the results showed in

383 this work. Differences between studies could be attributed mainly to the nature of the lipids

384 (carbon chain length, number of unsaturation), the temperature, the chosen technique or, for

385 indentation studies, the mathematical model chosen for the calculation of $R_{c}$ or $E^{57,58}$. The

386 presented results show that AFM indentation of liposome is a sensible method for comparison

387 between different lipid membranes.

388 For the sake of comparison with the SUV (tridimensional organization), the elasticity of

389 DPPC or DOPC membranes was calculated on the SLB (two dimensional organization) using

390 AFM load curves performed in the same conditions as for the breakthrough force

391 measurement. Only a larger MLCT probe was used for better sensibility. By attempting the

392 fit of equation (5), the Young's moduli (noted $E_{S L B}$ ) and bending modulus (noted $k_{C-S L B}$ )

393 were calculated using the classical Hertz model: 


$$
F=\frac{4 E_{S L B} \sqrt{R_{t i p}} \delta^{\frac{3}{2}}}{3\left(1-v^{2}\right)} \text { or } E_{S L B}=\frac{3}{4} \frac{k\left(1-v^{2}\right)}{\sqrt{R_{t i p} \delta}}
$$

394 For which corresponds a bending modulus:

$$
k_{C-S L B}=\frac{E_{S L B} \delta^{3}}{24\left(1-v^{2}\right)}
$$

395

396

Where the parameters are the same already cited for liposome membranes. In these equations,

$\delta$ is the indentation distance and $R_{\text {tip }}$ is the nominal radius of AFM MLCT tip $(\sim 20 \mathrm{~nm})$.

The use of contact mechanics using the Hertz model on SLB is limited by the effect of confinement of the sample between the tip and the underlying substrate ${ }^{59,60}$. Furthermore, lipid bilayers are not anisotropic materials. However, previous investigations suggested that

401 this calculation yet has comparative interest ${ }^{25,61}$. On SLBs, the Young modulus $(E)$ of DOPC

402 was found to be $27 \pm 8 \mathrm{MPa}$ with a corresponding bending modulus $k_{C}=(0.88 \pm 0.25) \times 10^{-19} \mathrm{~J}$, 403 while the $E$ and $k_{C}$ of DPPC were found to be $31 \pm 12 \mathrm{MPa}$ and $(2.03 \pm 0.79) \times 10^{-19} \mathrm{~J}$, 404 respectively. Therefore, the $E$ and $k_{C}$ parameters of DPPC and DOPC were less distinct when 405 measured on SLB than on SUV (Table 2). Meanwhile, more dispersed $E$ values were reported 406 in the literature for SLBs than for liposomes, thereby indicating the higher sensitivity of this 407 measurement upon experimental conditions in the case of SLB ${ }^{25,61,62}$ (Table 2). To conclude, 408 it is showed that membranes in the gel phase were more elastic and stiffer than the 409 membranes in fluid phase regardless the lipid organization (2D or 3D). However, the values of $E$ and $k_{C}$ were more robust when measured on liposomes than on SLBs, where the presence 
411 of the solid support affected the results depending on the indentation distance ${ }^{25}$. These

412 comparisons show that liposomes are adequate systems to determine the elastic properties of

413 lipid membranes. On the other hand, measurement of the breakthrough force is relevant for

414 SLBs.

415 The structure of molecules and the intermolecular interactions that lead lipid molecules to

416 self-assembly in bilayers, have a significant impact on the rigidity of these bilayers ${ }^{63,64}$. The

417 elasticity of the membrane allows it to accommodate strain without failure, which is essential

418 in many applications where the membrane need to resist shear stress, e.g. in transdermal

419 application, in blood vessels, the epithelial cells of the gastrointestinal tract, etc. The

420 hydrophobic interactions between the lipid molecules, in particular Van der Vaal interactions,

421 are the major responsible of the fluidity and the rigidity of the membrane. The double bond in

422 cis conformation interferes with hydrocarbon chain packing and destroys the cooperativity of

423 the chain interactions in the bilayer ${ }^{65,66}$.

424 The presence of this double bonds reduces the hydrophobic interactions by increasing the

425 distance between the hydrophobic moieties which decreases the stiffness of membrane ${ }^{45}$.

426 IV. CONCLUSION:

427 The nano-indentation of DOPC and DPPC liposomes by AFM probe at low force load was

428 able to provide local and discriminant information on the elastic properties of bilayer

429 membranes in 3D organization without plastic deformation. The Young's moduli $E$ and

430 bending rigidity values $k_{C}$ of gel phase DPPC membranes is significantly higher than that of 
431 fluid phase DOPC ones at $20^{\circ} \mathrm{C}$, in agreement with their different phase state. The

432 perspective of this work is to investigate the mechanical properties of biological membranes

433 with complex chemical composition and fluid/gel phase coexistence. Thanks to the high

434 lateral resolution of AFM, it is expected that phase separation and correlated nanomechanical

435 contrast may be measured directly on model liposomes or even biological vesicles.

\section{$436 \quad$ V. ACKNOWLEDGMENTS}

437 The Asylum Research MFP3D-BIO atomic force microscope was funded by the European 438 Union (FEDER), the French Ministry of Education and Research, INRA, Conseil Général 35

439 and Rennes Métropole. The doctoral fellowship of author Et-Thakafy was funded by INRA

440 CEPIA and Région Bretagne under the grant ARED 8806.

\section{VI. APPENDIX:}

442 The Young modulus values were also obtained using radius of curvature $R_{C}$ of the whole

443 individual liposomes. It was calculated using $H$ and $W$ of the individual liposomes ${ }^{67}$

444 , as:

$$
R_{C}=\frac{0.25 W^{2}+H^{2}}{2 H}
$$

445 The mechanical data obtained from literature were expressed either as the Young modulus $E$,

446 the bending rigidity $k_{C}$ or both. To complete and compare literature information in table 2; we

447 used the following equations to provide both parameters for each cited reference:

448 For liposome (shell model): 


$$
k_{C}=\frac{E \mathrm{~d}^{3}}{12\left(1-v^{2}\right)} \quad \Leftrightarrow \quad E=\frac{12\left(1-v^{2}\right) k_{C}}{\mathrm{~d}^{3}}=\frac{9 k_{C}}{\mathrm{~d}^{3}}
$$

449 For supported lipid bilayer (Hertz model):

$$
k_{C-S L B}=\frac{E_{S L B} \mathrm{~d}^{3}}{24\left(1-v^{2}\right)} \quad \Leftrightarrow \quad E_{S L B}=\frac{24\left(1-v^{2}\right) k_{C-S L B}}{\mathrm{~d}^{3}}=\frac{18 k_{C-S L B}}{\mathrm{~d}^{3}}
$$

450

451

452

453

454

455

456

457

458

459

460

461

462

463

464

465

466

467

468

469

470

471

472

473

$E$ : Young modulus

$k_{C}$ : bending rigidity

$v$ : Poisson coefficient $(0.5)$

$\mathrm{d}$ : membrane thickness

For the publication where the membrane thickness not shown, the following values were used

to calculate the elasticity or the bending rigidity:

$\mathrm{d}(\mathrm{DMPC})=3.6 \mathrm{~nm}^{44}$

$\mathrm{d}(\mathrm{DOPC})=3.9 \mathrm{~nm}^{\text {(present work })}$

\section{REFERENCES}

(1) Lasic, D. D. Novel Applications of Liposomes. Trends Biotechnol. 1998, 16, 307-321.

(2) Liu, W.; Ye, A.; Liu, C.; Liu, W.; Singh, H. Structure and Integrity of Liposomes Prepared from Milk- or Soybean-Derived Phospholipids during in Vitro Digestion. Eood Res. Int. 2012, 48, 499-506.

(3) Théry, C.; Ostrowski, M.; Segura, E. Membrane Vesicles as Conveyors of Immune Responses. Nat.Rev. Immunol. 2009, 9, 581-593.

(4) van der Meel, R.; Fens, M. H.; Vader, P.; van Solinge, W. W.; Eniola-Adefeso, O.; Schiffelers, R. M. Extracellular Vesicles as Drug Delivery Systems: Lessons from the Liposome Field. J. Controlled Release 2014, 195, 72-85.

(5) Chapman, D. Phase Transitions and Fluidity Characteristics of Lipids and Cell Membranes. O.Rev. Biophvs. 1975, 8, 185-235.

(6) Lipowsky, R. Remodeling of Membrane Compartments: Some Consequences of Membrane Fluidity. Biol. Chem. 2014, 395. 
(7) Neubauer, M. P.; Poehlmann, M.; Fery, A. Microcapsule Mechanics: From Stability to

(8) Sitterberg, J.; Özcetin, A.; Ehrhardt, C.; Bakowsky, U. Utilising Atomic Force Microscopy for the Characterisation of Nanoscale Drug Delivery Systems. Eur. J. Pharm. Biopharm. 2010, 74, 2-13.

(9) Briuglia, M.-L.; Rotella, C.; McFarlane, A.; Lamprou, D. A. Influence of Cholesterol on Liposome Stability and on in Vitro Drug Release. Drug Deliv. Transl. Res. 2015, 5, 231-242.

(10) Duangjit, S.; Pamornpathomkul, B.; Opanasopit, P.; Rojanarata, T.; Obata, Y.; Takayama, K.; Ngawhirunpat, T. Role of the Charge, Carbon Chain Length, and Content of Surfactant on the Skin Penetration of Meloxicam-Loaded Liposomes. Int. J. Nanomedicine 2014, 9, 2005.

(11) Maherani, B.; Arab-Tehrany, E.; Kheirolomoom, A.; Cleymand, F.; Linder, M. Influence of Lipid Composition on Physicochemical Properties of Nanoliposomes Encapsulating Natural Dipeptide Antioxidant L-Carnosine. Eood Chem. 2012, 134, 632-640.

(12) Tokudome, Y.; Uchida, R.; Yokote, T.; Todo, H.; Hada, N.; Kon, T.; Yasuda, J.; Hayashi, H.; Hashimoto, F.; Sugibayashi, K. Effect of Topically Applied Sphingomyelin-Based Liposomes on the Ceramide Level in a Three-Dimensional Cultured Human Skin Model. J Linosome Res. 2010, 20, 49-54.

(13) Yoshimoto, M.; Todaka, Y. Phase Transitioninduced Rapid Permeabilization of Liposome Membranes Composed of Milksphingomyelin. Eur. J. Lipid Sci. Technol. 2014, 116, 226-231.

(14) Inoue, K. Permeability Properties of Liposomes Prepared from Dipalmitoyllecithin, Dimyristoyllecithin, Egg Lecithin, Rat Liver Lecithin and Beef Brain Sphingomyelin. Biochim. Bionhvs. Acta BBA-Biomembr. 1974, 339, 390-402.

(15) Calò, A.; Reguera, D.; Oncins, G.; Persuy, M.-A.; Sanz, G.; Lobasso, S.; Corcelli, A.; Pajot-Augy, E.; Gomila, G. Force Measurements on Natural Membrane Nanovesicles Reveal a Composition-Independent, High Young's Modulus. Nanoscale 2014, 6, 22752285.

(16) Delorme, N.; Fery, A. Direct Method to Study Membrane Rigidity of Small Vesicles Based on Atomic Force Microscope Force Spectroscopy. Phys. Rev. E 2006, 74.

(17) Laney, D. E.; Garcia, R. A.; Parsons, S. M.; Hansma, H. G. Changes in the Elastic Properties of Cholinergic Synaptic Vesicles as Measured by Atomic Force Microscopy. Biophvs. J. 1997, 72, 806.

(18) Li, S.; Eghiaian, F.; Sieben, C.; Herrmann, A.; Schaap, I. A. Bending and Puncturing the Influenza Lipid Envelope. Biophvs. J. 2011, 100, 637-645.

(19) Liang, X.; Mao, G.; Simon Ng, K. . Probing Small Unilamellar EggPC Vesicles on Mica Surface by Atomic Force Microscopy. Colloids Surf. B Biointerfaces 2004, 34 , 41-51.

(20) Ramachandran, S.; Quist, A. P.; Kumar, S.; Lal, R. Cisplatin Nanoliposomes for Cancer Therapy: AFM and Fluorescence Imaging of Cisplatin Encapsulation, Stability, Cellular Uptake, and Toxicity. Langmuir 2006, 22, 8156-8162.

(21) Liang, X.; Mao, G.; Ng, K. Y. S. Mechanical Properties and Stability Measurement of Cholesterol-Containing Liposome on Mica by Atomic Force Microscopy. J. Colloid Interface Sci. 2004, 278, 53-62.

(22) Benesch, M. G.; McElhaney, R. N. A Comparative Calorimetric Study of the Effects of Cholesterol and the Plant Sterols Campesterol and Brassicasterol on the Thermotropic Phase Behavior of Dipalmitoylphosphatidylcholine Bilayer Membranes. Biochim. Biophvs. Acta BBA-Biomembr. 2014, 1838, 1941-1949. 
(23) Redondo-Morata, L.; Giannotti, M. I.; Sanz, F. Influence of Cholesterol on the Phase Transition of Lipid Bilayers: A Temperature-Controlled Force Spectroscopy Study. Lanomuir 2012, 28, 12851-12860. Garcia-Manyes, S.; Sanz, F. Nanomechanics of Lipid Bilayers by Force Spectroscopy with AFM: A Perspective. Biochim. Biophvs. Acta BBA-Biomembr. 2010, 1798, 741749.

(25) Picas, L.; Rico, F.; Scheuring, S. Direct Measurement of the Mechanical Properties of Lipid Phases in Supported Bilayers. Biophvs. J. 2012, 102, L01-L03.

(26) Ahmed, S.; Nikolov, Z.; Wunder, S. L. Effect of Curvature on Nanoparticle Supported Lipid Bilayers Investigated by Raman Spectroscopy. J. Phvs. Chem. B 2011, 115, 13181-13190.

(27) Marbella, L. E.; Yin, B.; Spence, M. M. Investigating the Order Parameters of Saturated Lipid Molecules under Various Curvature Conditions on Spherical Supported Lipid Bilayers. J.Phvs.Chem.B 2015, 119, 4194-4202.

(28) Sorkin, R.; Dror, Y.; Kampf, N.; Klein, J. Mechanical Stability and Lubrication by Phosphatidylcholine Boundary Layers in the Vesicular and in the Extended Lamellar Phases. Langmuir 2014, 30, 5005-5014.

(29) Buchner Santos, E.; Morris, J. K.; Glynos, E.; Sboros, V.; Koutsos, V. Nanomechanical Properties of Phospholipid Microbubbles. Langmuir 2012, 28, 5753-5760.

(30) Prenner, E.; Chiu, M. Differential Scanning Calorimetry: An Invaluable Tool for a Detailed Thermodynamic Characterization of Macromolecules and Their Interactions. J.Pharm. Bioallied Sci. 2011, 3, 39.

(31) Bizien, T.; Ameline, J.-C.; Yager, K. G.; Marchi, V.; Artzner, F. Self-Organization of Quantum Rods Induced by Lipid Membrane Corrugations. Langmuir 2015, 31, 1214812154.

(32) Blanton, T.; Barnes, C.; Lelental, M. Preparation of Silver Behenate Coatings to Provide Low-to Mid-Angle Diffraction Calibration. J. Appl. Crustallogr. 2000, 33, 172-173.

(33) Gaillard, C.; Douliez, J.-P. Cryo-TEM and AFM for the Characterization of Vesiclelike Nanoparticle Dispersions and Self-Assembled Supramolecular Fatty-Acid-Based Structures: A Few Examples. Curr. Microsc. Contrib. Adv. Sci. Technol. 2012, 5, 912922.

(34) Murthy, A. V. R.; Guyomarc'h, F.; Lopez, C. Cholesterol Decreases the Size and the Mechanical Resistance to Rupture of Sphingomyelin Rich Domains, in Lipid Bilayers Studied as a Model of the Milk Fat Globule Membrane. Langmuir 2016, 32, 67576765.

(35) Fa, N.; Ronkart, S.; Schanck, A.; Deleu, M.; Gaigneaux, A.; Goormaghtigh, E.; Mingeot-Leclercq, M.-P. Effect of the Antibiotic Azithromycin on Thermotropic Behavior of DOPC or DPPC Bilayers. Chem. Phvs. Linids 2006, 144, 108-116.

(36) Fritzsching, K. J.; Kim, J.; Holland, G. P. Probing Lipid-cholesterol Interactions in DOPC/eSM/Chol and DOPC/DPPC/Chol Model Lipid Rafts with DSC and 13C SolidState NMR. Biochim. Biophvs. Acta BBA - Biomembr. 2013, 1828, 1889-1898.

(37) Grabielle-Madelmont, C.; Perron, R. Calorimetric Studies on Phospholipid - water Systems: I. D1-Dipalmitoylphosphatidylcholine (DPPC)—water System. J. Colloid Interface Sci. 1983, 95, 471-482.

(38) Boni, L. T.; Minchey, S. R.; Perkins, W. R.; Ahl, P. L.; Slater, J. L.; Tate, M. W.; Gruner, S. M.; Janoff, A. S. Curvature Dependent Induction of the Interdigitated Gel Phase in DPPC Vesicles. Biochim. Biophvs. Acta BBA-Biomembr. 1993, 1146, $247-$ 257. 
(39) Kuntsche, J.; Horst, J. C.; Bunjes, H. Cryogenic Transmission Electron Microscopy (Cryo-TEM) for Studying the Morphology of Colloidal Drug Delivery Systems. Int. $J$. Pharm. 2011, 417, 120-137.

(40) Colas, J.-C.; Shi, W.; Rao, V. M.; Omri, A.; Mozafari, M. R.; Singh, H. Microscopical

(41) Guyomarc'h, F.; Zou, S.; Chen, M.; Milhiet, P.-E.; Godefroy, C.; Vié, V.; Lopez, C. Investigations of Nisin-Loaded Nanoliposomes Prepared by Mozafari Method and Their Bacterial Targeting. Micron 2007, 38, 841-847. Milk Sphingomyelin Domains in Biomimetic Membranes and the Role of Cholesterol: Morphology and Nanomechanical Properties Investigated Using AFM and Force Spectroscopy. Langmuir 2014, 30, 6516-6524.

(42) Murthy, A. V. R.; Guyomarc'h, F.; Lopez, C. The Temperature-Dependent Physical State of Polar Lipids and Their Miscibility Impact the Topography and Mechanical Properties of Bilayer Models of the Milk Fat Globule Membrane. Biochim. Biophvs. Acta BBA - Biomembr. 2016, 1858, 2181-2190.

(43) Leonenko, Z. V.; Finot, E.; Ma, H.; Dahms, T. E. S.; Cramb, D. T. Investigation of Temperature-Induced Phase Transitions in DOPC and DPPC Phospholipid Bilayers Using Temperature-Controlled Scanning Force Microscopy. Bionhvs.J. 2004, 86, 3783-3793.

(44) Nagle, J. F.; Tristram-Nagle, S. Structure of Lipid Bilayers. Biochim.Biophvs.Acta BBA-Rev. Biomembr. 2000, 1469, 159-195.

(45) Rawicz, W.; Olbrich, K.; McIntosh, T.; Needham, D.; Evans, E. Effect of Chain Length and Unsaturation on Elasticity of Lipid Bilayers. Bionhvs.J. 2000, 79, 328-339.

(46) Garcia-Manyes, S.; Oncins, G.; Sanz, F. Effect of Temperature on the Nanomechanics of Lipid Bilayers Studied by Force Spectroscopy. Bionhvs.J. 2005, 89, 4261-4274.

(47) Redondo-Morata, L.; Oncins, G.; Sanz, F. Force Spectroscopy Reveals the Effect of Different Ions in the Nanomechanical Behavior of Phospholipid Model Membranes: The Case of Potassium Cation. Biophvs. J. 2012, 102, 66-74.

(48) Jacquot, A.; Francius, G.; Razafitianamaharavo, A.; Dehghani, F.; Tamayol, A.; Linder, M.; Arab-Tehrany, E. Morphological and Physical Analysis of Natural PhospholipidsBased Biomembranes. PLOS ONE 2014, 9, e107435.

(49) Reissner, E. Note on the Membrane Theory of Shell of Revolution. Stud. Appl. Math. 1947, 26, 290-293.

(50) Fery, A.; Weinkamer, R. Mechanical Properties of Micro- and Nanocapsules: SingleCapsule Measurements. Polvmer 2007, 48, 7221-7235.

(51) Glaubitz, M.; Medvedev, N.; Pussak, D.; Hartmann, L.; Schmidt, S.; Helm, C. A.; Delcea, M. A Novel Contact Model for AFM Indentation Experiments on Soft Spherical Cell-like Particles. Soft Matter 2014, 10, 6732.

(52) Berry, J. D.; Mettu, S.; Dagastine, R. R. Precise Measurements of Capsule Mechanical Properties Using Indentation. Soft Matter 2017, 13, 1943-1947.

(53) Makino, K.; Yamada, T.; Kimura, M.; Oka, T.; Ohshima, H.; Kondo, T. Temperatureand Ionic Strength-Induced Conformational Changes in the Lipid Head Group Region of Liposomes as Suggested by Zeta Potential Data. Biophvs. Chem. 1991, 41, 175-183.

(54) Meleard, P.; Gerbeaud, C.; Pott, T.; Fernandez-Puente, L.; Bivas, I.; Mitov, M. D.; Dufourcq, J.; Bothorel, P. Bending Elasticities of Model Membranes: Influences of Temperature and Sterol Content. Biophvs. J. 1997, 72, 2616.

(55) Duwe, H. de; Sackmann, E. Bending Elasticity and Thermal Excitations of Lipid Bilayer Vesicles: Modulation by Solutes. Phvs. Stat. Mech. Its Appl. 1990, 163, 410428. 
(56) Hantz, E.; Cao, A.; Escaig, J.; Taillandier, E. The Osmotic Response of Large Unilamellar Vesicles Studied by Quasielastic Light Scattering. Biochim.Biophvs. Acta BBA-Biomembr. 1986, 862, 379-386.

(57) Brochu, H.; Vermette, P. Young's Moduli of Surface-Bound Liposomes by Atomic

\section{TABLES}

660

Table1: Geometrical parameters of dioleoylphosphatidylcholine (DOPC) or 
663 from which the mean diameter of a sphere of equivalent volume was deduced (Eq.2). The 664 mean values of DOPC and DPPC membrane thicknesses were measured using the jump 665 distance $\mathrm{d}$ from breakthrough force curves $(\mathrm{n}=30)$ recorded in $\mathrm{PIPES} / \mathrm{NaCl} / \mathrm{CaCl}$ buffer, $\mathrm{pH}$ $666 \quad 6.7$ at $20^{\circ} \mathrm{C}$.

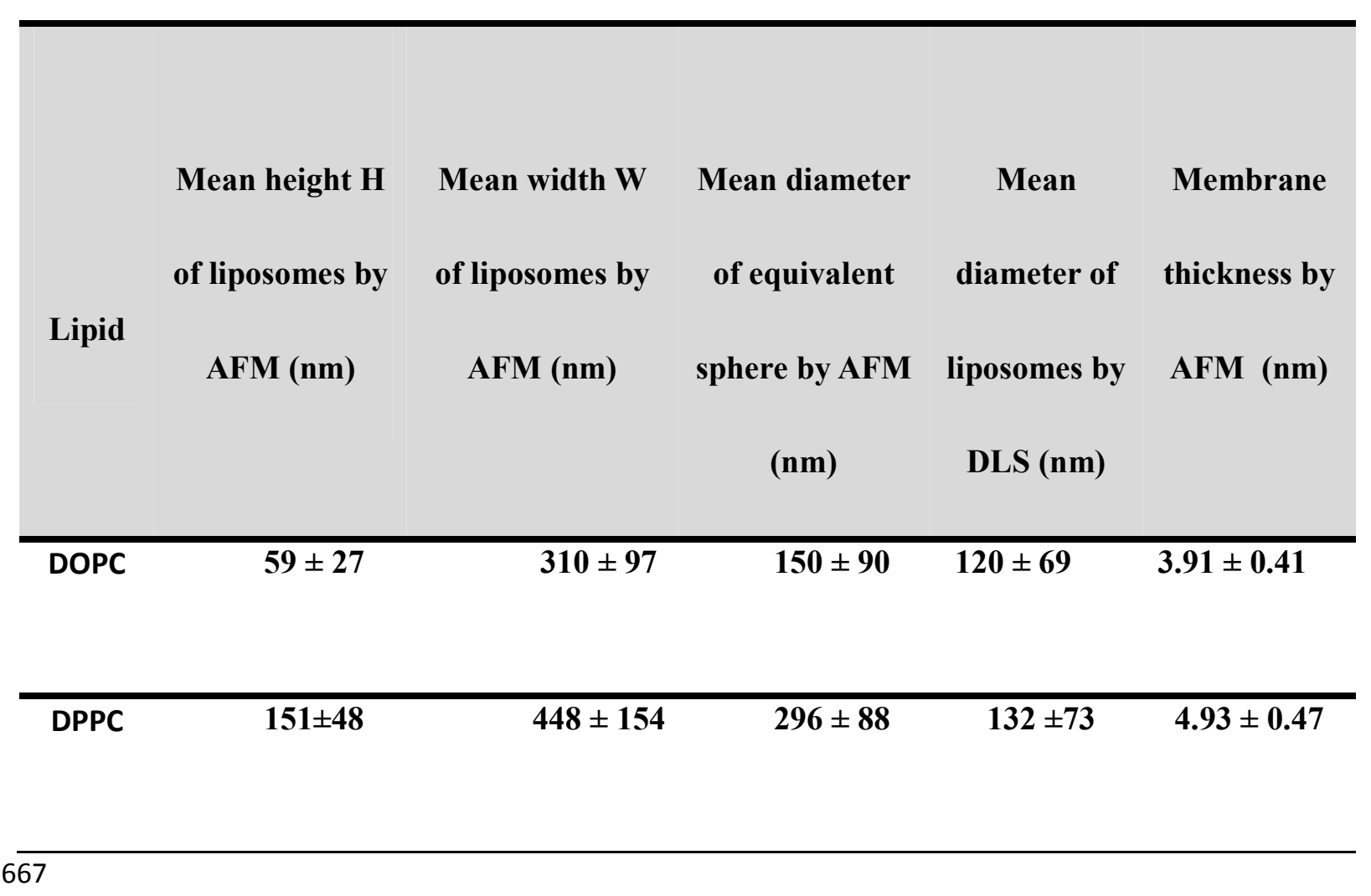

668 
669

670 Table 2: Comparison of the bending modulus $\left(k_{C}\right)$ and Young modulus values $(E)$ of

671 liposomes or of supported lipid bilayers in the fluid or gel phase reported in the literature

672 using different techniques as indicated. Abbreviations stand for: EggPC $=$ mixture of

673 unsaturated (54.8 wt. \%) and saturated (45.2 wt. \%) phosphatidylcholine; DMPC $=1,2-$

674 dimyristoyl-sn-glycero-3-phosphocholine; ESM = egg sphingomyelin; Chol = cholesterol.

675 Values in italics were calculated by the authors using calculations described in the Appendix

676 (eq.A.2; A.3)

677

678

679

680

681

682

683 


\begin{tabular}{|c|c|c|c|c|c|}
\hline Reference & Lipid & Technique & Phase & $\begin{array}{c}\text { Bending } \\
\text { modulus } k_{C} \\
\left(\times 10^{-19} \mathrm{~J}\right)\end{array}$ & $\begin{array}{c}\text { Young } \\
\text { modulus } E \\
(\mathrm{MPa})\end{array}$ \\
\hline \multirow{3}{*}{ Present work } & \multicolumn{4}{|c|}{ Liposomes (3D) } & \\
\hline & DOPC & $\begin{array}{c}\text { AFM } \\
\text { spectroscopy }\end{array}$ & Fluid & 0.9 & 13 \\
\hline & DPPC & $\begin{array}{c}\text { AFM } \\
\text { spectroscopy }\end{array}$ & Gel & 15.50 & 116 \\
\hline 16 & DPPC & $\begin{array}{c}\text { AFM } \\
\text { spectroscopy }\end{array}$ & Gel & 13.54 & 110 \\
\hline 21 & Egg PC & $\begin{array}{c}\text { AFM } \\
\text { spectroscopy }\end{array}$ & Fluid & 0.27 & 1.97 \\
\hline 45 & $\begin{array}{c}\text { synthetic } \\
\text { phospholipids } \\
(18: 1)\end{array}$ & $\begin{array}{l}\text { Micropipette } \\
\text { pressurization }\end{array}$ & Fluid & 0.90 & 12.70 \\
\hline 54 & DMPC & $\begin{array}{l}\text { Phase contrast } \\
\text { microscopy }\end{array}$ & Fluid & 1.27 & 26 \\
\hline 55 & DMPC & $\begin{array}{l}\text { Phase contrast } \\
\text { microscopy }\end{array}$ & Fluid & 1.15 & 24 \\
\hline 56 & DOPC & $\begin{array}{l}\text { Osmotic } \\
\text { swelling }\end{array}$ & Fluid & 1.06 & 15 \\
\hline
\end{tabular}

\section{Supported bilayers (2D)}

\begin{tabular}{|c|c|c|c|c|c|}
\hline \multirow[t]{2}{*}{ Present work } & DOPC & $\begin{array}{c}\text { AFM } \\
\text { spectroscopy }\end{array}$ & Fluid & 0.88 & 27 \\
\hline & DPPC & $\begin{array}{c}\text { AFM } \\
\text { spectroscopy }\end{array}$ & Gel & 2.03 & 31 \\
\hline \multirow[t]{2}{*}{28} & DOPC & $\begin{array}{c}\text { AFM } \\
\text { spectroscopy }\end{array}$ & Fluid & 1.69 & 19.3 \\
\hline & DPPC & $\begin{array}{c}\text { AFM } \\
\text { spectroscopy }\end{array}$ & Gel & 2.33 & 28.1 \\
\hline \multirow[t]{2}{*}{61} & DOPC & $\begin{array}{c}\text { AFM } \\
\text { spectroscopy }\end{array}$ & Fluid & 4.61 & 80 \\
\hline & ESM/Chol & $\begin{array}{c}\text { AFM } \\
\text { spectroscopy }\end{array}$ & Liquid ordered & 12.94 & 140 \\
\hline \multirow[t]{2}{*}{62} & DOPC & $\begin{array}{c}\text { AFM } \\
\text { spectroscopy }\end{array}$ & Fluid & 8.65 & 150 \\
\hline & $\begin{array}{r}\text { ESM/Chol } \\
\text { ACS }\end{array}$ & $\begin{array}{c}\text { AFM } \\
\text { spectHesc5pyir }\end{array}$ & $\begin{array}{l}\text { Liquid ordered } \\
\text { ment }\end{array}$ & 27.72 & 300 \\
\hline
\end{tabular}




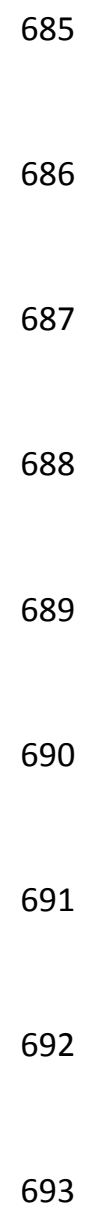




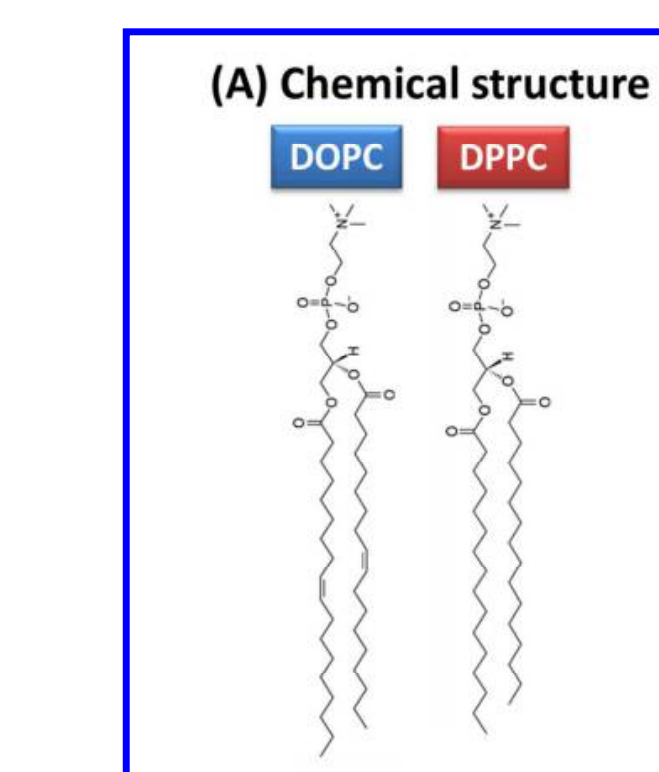

(C) Phase state in MLV

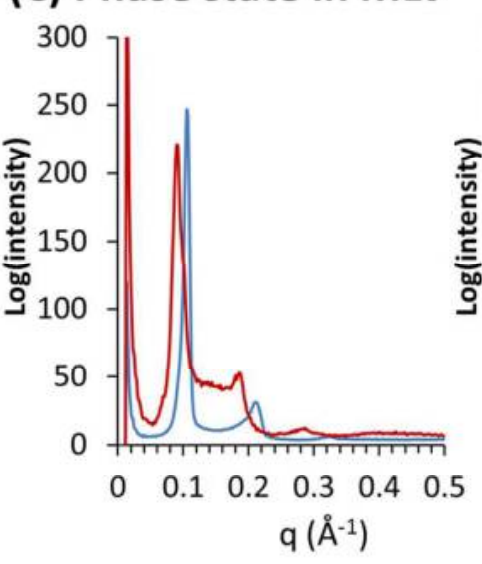

\section{(B) Thermotropic properties}

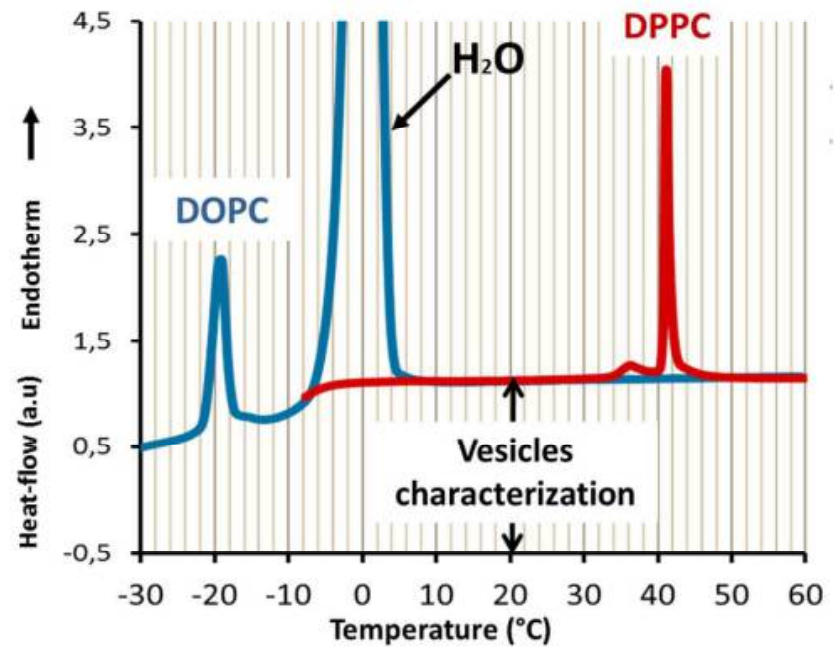

(D) Phase state of DPPC in SUV
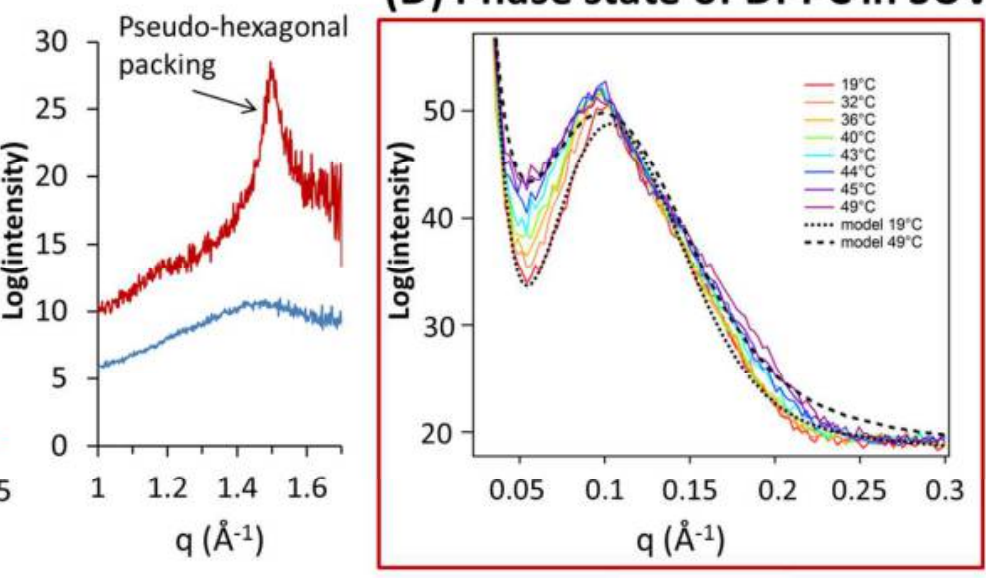

696

697 Figure 1: (A) Molecular structures of the unsaturated DOPC (dioleoylphosphatidylcholine)

698 and saturated DPPC (dipalmitoylphosphatidylcholine). (B) Differential scanning calorimetry

699 thermograms of DOPC (blue trace) and DPPC (red trace) multilamellar vesicles recorded on

700 heating at $2^{\circ} \mathrm{C} \cdot \mathrm{min}^{-1}$. (C) X-ray diffraction patterns of DOPC and DPPC fully hydrated

701 multilamellar vesicles recorded at $20^{\circ} \mathrm{C}$ at small (left) and wide (right) angles. (D) Small

702 angle X-ray Scattering of DPPC SUV recorded on heating. Unilamellar SAXS model at low 
703 and high temperature are superimposed. All experiments were performed in aqueous

704 PIPES/ $\mathrm{NaCl} / \mathrm{CaCl}_{2}$ medium at $\mathrm{pH}=6.7$.

705 


\section{(C) AFM topography}

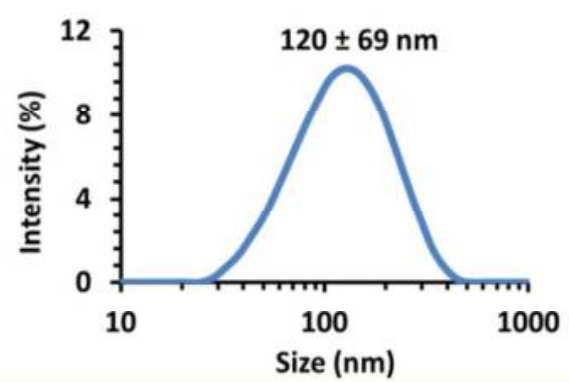

(E) Size distribution

(F) AFM topography
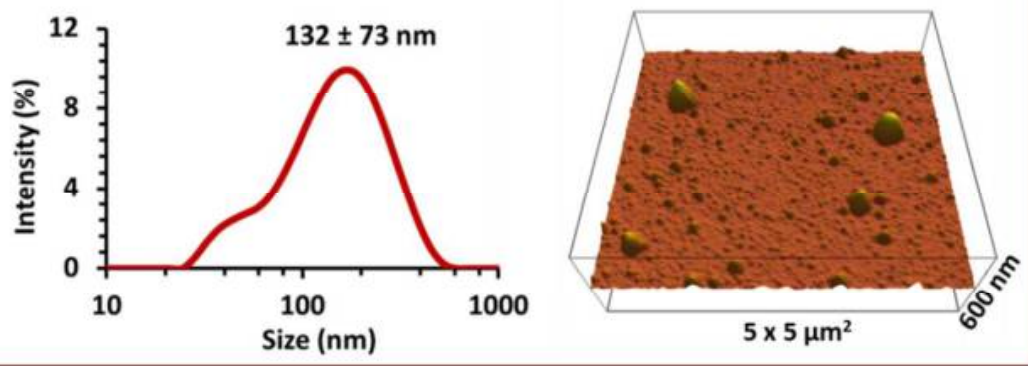

707

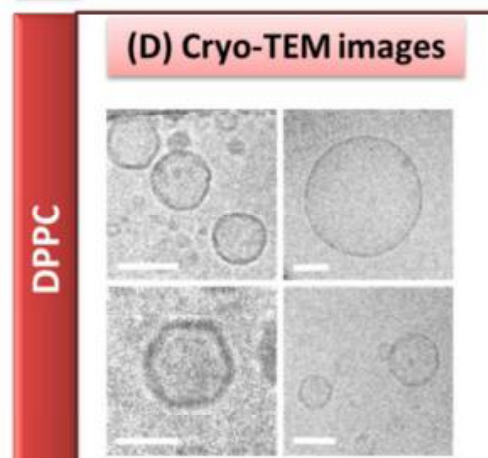

708

Figure2: Characterization of the shape and size of DOPC (dioleoylphosphatidylcholine) or

709

DPPC (dipalmitoylphosphatidylcholine) liposomes. (A) and (D) Cryo-TEM images of the

710 DOPC and DPPC liposomes, respectively; scale bars are $100 \mathrm{~nm}$. (B) and (E) Dynamic light

711 scattering size distribution in intensity of the DOPC and DPPC liposome suspensions,

712 respectively; and $(\mathrm{C})$ and $(\mathrm{F})$ typical AFM 3D images of DOPC and DPPC liposomes,

713 respectively. All experiments were performed in aqueous $\mathrm{PIPES} / \mathrm{NaCl} / \mathrm{CaCl}_{2}$ medium at $\mathrm{pH}=$

$714 \quad 6.7$ and at $20^{\circ} \mathrm{C}$. 


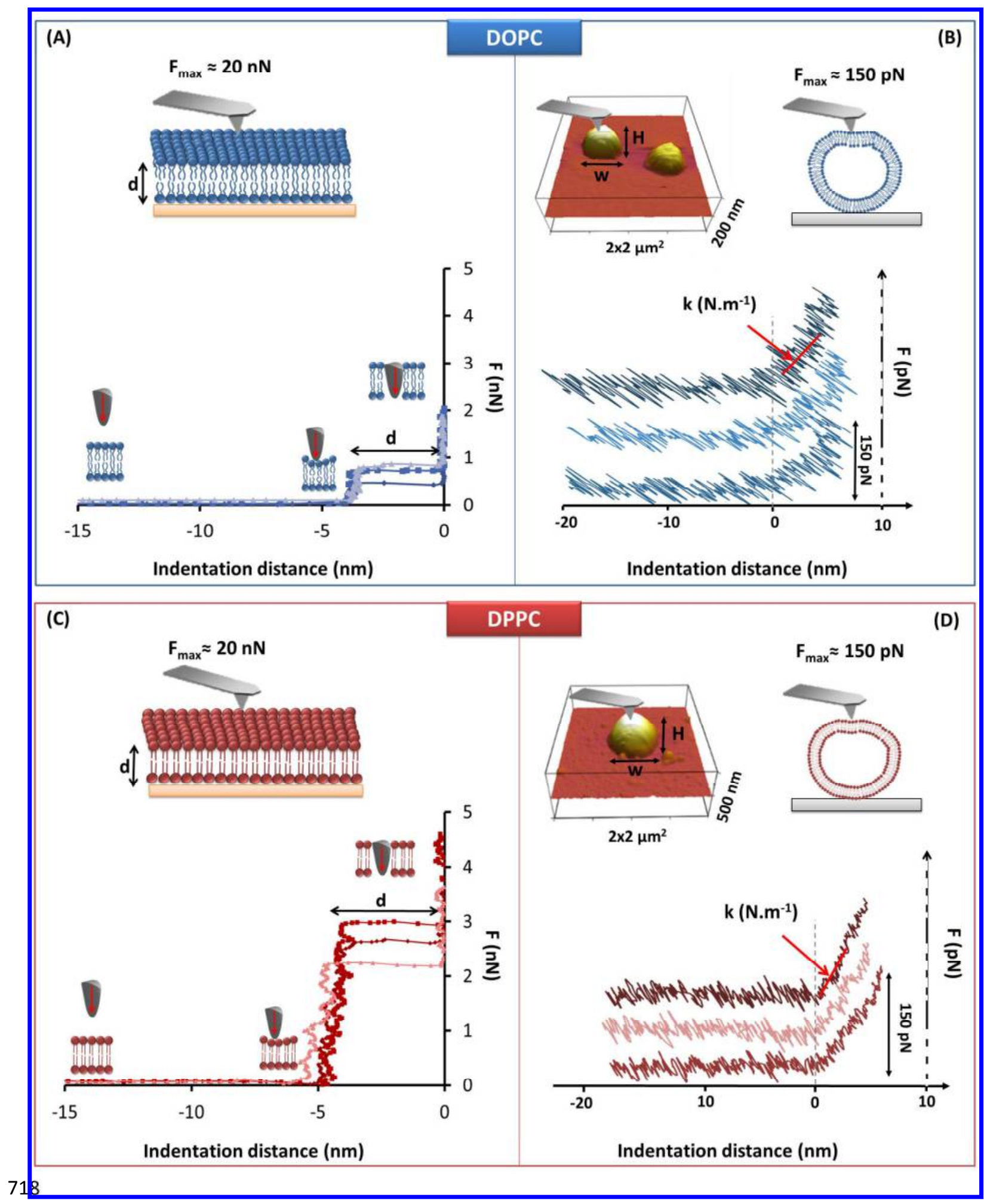


720 Figure 3: AFM indentation measurement on DOPC (dioleoylphosphatidylcholine, in blue) or

721 DPPC (dipalmitoylphosphatidylcholine, in red) liposomes adsorbed on silicon substrate. (A)

722 and (C) show the breakthrough force curves obtained as a result of tip penetration into DOPC

723 or DPPC supported lipid bilayers, respectively. The average bilayer thickness value d was

724 measured from the jump-through distance $(n=50)$. (B) and (D) show typical force curves

725 acquired during indentation of, respectively, DOPC or DPPC liposomes in the elastic regime;

726 in order to infer the bilayer stiffness $k$ from the slope after tip-membrane contact. For the sake

727 of clarity, the force curves are shifted along the Y axis. All measurements were recorded in 728 aqueous PIPES/NaCl/CaCl 2 medium at $\mathrm{pH}=6.7$ and at $20^{\circ} \mathrm{C}$. 


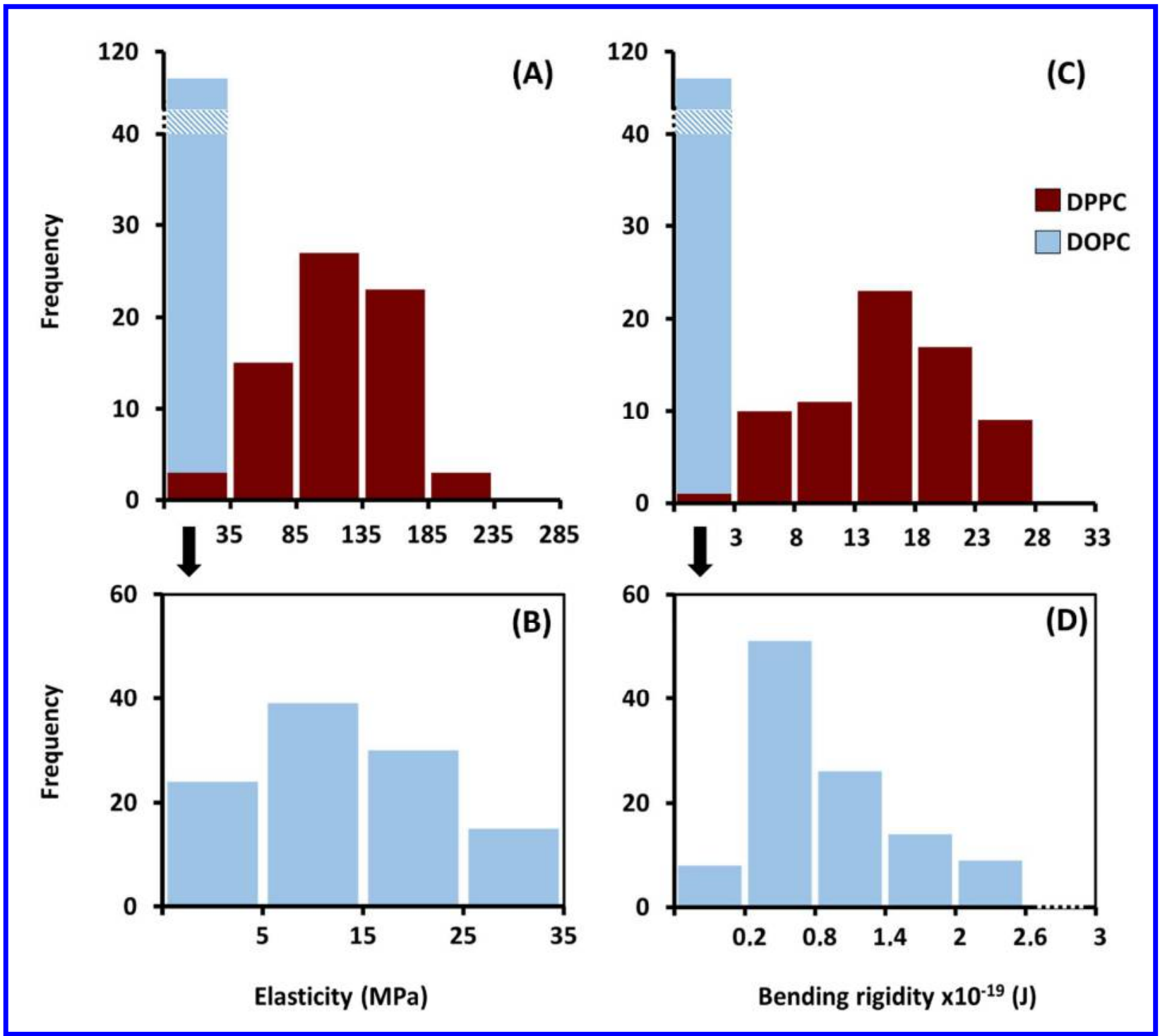

730

731

732

733

734 Figure 4: Distributions of the Young moduli $E$ and of the bending rigidity $k_{C}$, independent of

735 liposome size, of DOPC $(n=108)$ and DPPC $(n=71)$. (A) and (C) show the superposition of

736 both DOPC and DPPC frequency distributions for $E$ and $k_{C}$, respectively. (B) and (D) show 
1

2

3

4

5

6

7

8

9

10

11

12

13

14

15

16

17

18

19

20

21

22

23

24

25

26

27

28

29

30

31

32

33

34

35

36

37

38

39

40

41

42

43

44

45

46

47

48

49

50

51

52

53

54

55

56

57

58

59

60

737 respective enlargements of the $E$ and $k_{C}$ frequency distributions for the DOPC liposomes. All

738 measurements were recorded in aqueous PIPES $/ \mathrm{NaCl} / \mathrm{CaCl}{ }_{2}$ medium at $\mathrm{pH}=6.7$ and at $20^{\circ} \mathrm{C}$.

739

740 


\section{Table of contents graphic}

742

743

744

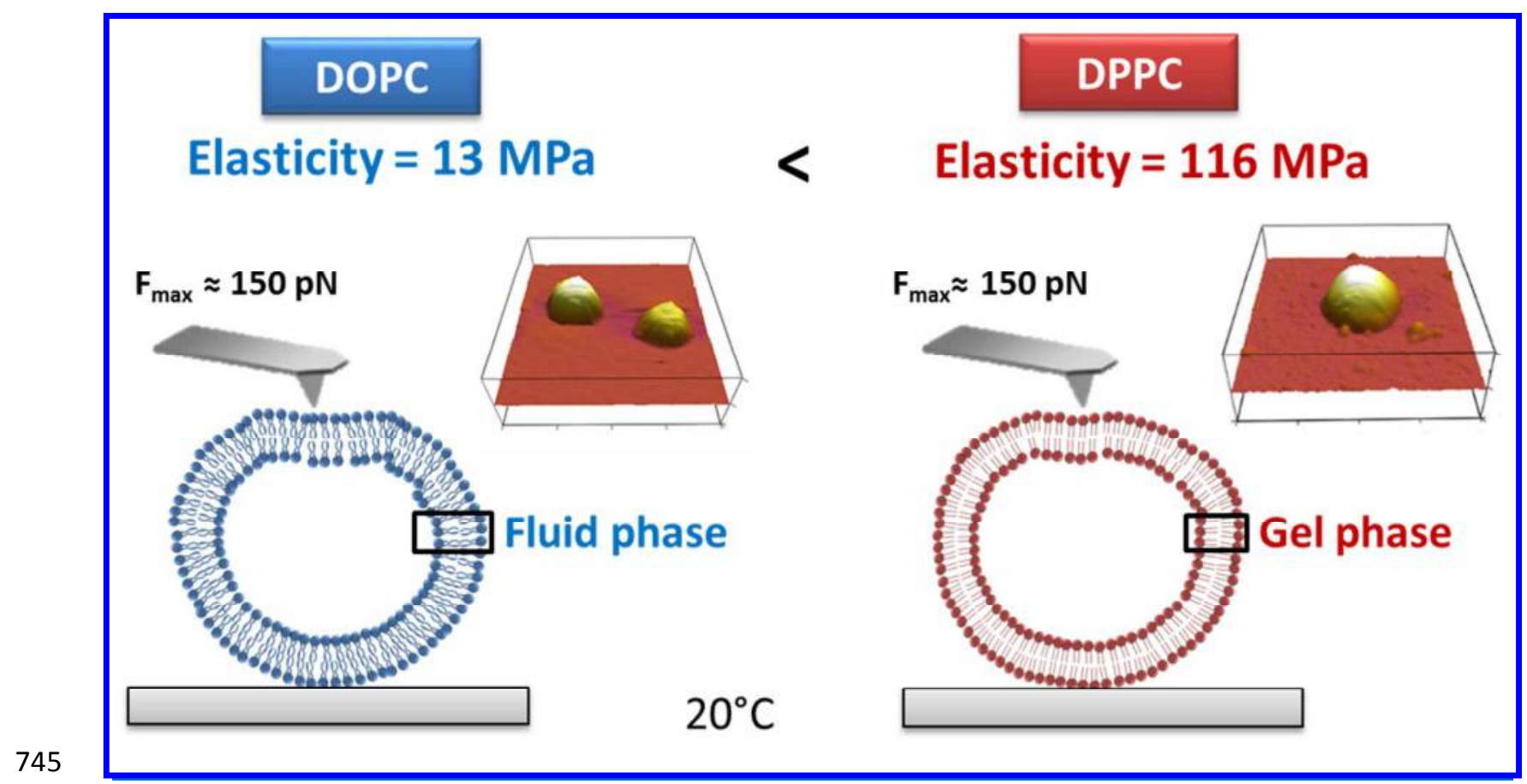

